\title{
Multi-Center Phase II Study of the Clinical Use of the Avicenna Roboflex
}

\author{
Jens Rassweiler* \\ Department of Urology, University of Heidelberg, Germany
}

Submission: March 03, 2017; Published: March 27, 2017

*Corresponding author: Jens Rassweiler, Department of Urology, University of Heidelberg, Germany, Tel: +497131492401;

Email: jens.rassweiler@slk-kliniken.de

\begin{abstract}
Objectives: To present the results of a multicentric phase-II study, representing the next step according to the IDEAL-criteria in the evualuation process of robot-assisted flexible ureterorenocopy.

Material and methods: The Avicenna Roboflex consists of a console and the manipulator. Peri-operative data from 266 patients who underwent robotic retrograde intra-renal stone surgery (robRIRS) between January 2015 and March 2016 at two centres (Heilbronn, Ankara) were recorded prospectively. Six surgeons were involved in the study. We treated 90 females and 176 male patients with a mean age of 55 (2576) years. 118 stones were located on the right and 148 on the left side. Mean number of stones was 1.8 with a mean stone burden of 1620 $(98-10600) \mathrm{mm}^{3} ; 43 \%$ of the patients were pre-stented. A $12 / 14 \mathrm{~F}$ access sheath was used in all cases; laser fragmentation was accomplished by a high-energy laser device applying actual concepts of laser lithotripsy.
\end{abstract}

Results: Preparation of the robot required 4:30min (range 3-8min); docking time was 4 min (range 1-29min). Console time to identify the stone amounted $4 \mathrm{~min}$ (range 1-12min.); total operating time was $96 \mathrm{~min}$ (range 58-193min) including a console time of 65(16-174) min. Laser lithotripsy was performed in 245 patients (92\%), 112(42\%) patients required extraction of larger fragments using N-gage-basket. The stone clearance rate amounted $25(9-101) \mathrm{mm}^{3} / \mathrm{min}$. Total fluoroscopy time was time 2:30min with a radiation dosis of $297 \mathrm{cGy}^{*} \mathrm{~cm}^{2}$. $117(44 \%)$ of our patients were stented post-operatively of which $75(28 \%)$ had the stent on a string removed on day 1 together with the Foley catheter. In $2(0.7 \%)$ cases we had to convert to classical FURS due to technical failure of the robot. Median post-operative hospital stay was 1(1-30) day. We encountered one case of urosepsis (Clavien 3a) requiring treatment on an intensive care unit.

Conclusion: In this setting, Avicenna Roboflex proved to be robust with only two cases of technical failure requiring conversion to classical FURS. The radiation exposure for the surgeon can be significantly reduced. In conclusion, we were able to integrate the device easily in our daily routine.

Keywords: Avicenna roboflex; Intra-renal stone; Ureteroscopy

Abbreviations: robRIRS: robotic Retrograde Intra-Renal Stone Surgery; SD: Standard Deviation; NIRF: Near-Infrared Fluorescent

\section{Introduction}

Management of urolithiasis changed dramatically during the last decades. Whereas in the eighties and nineties of last century extracorporeal shock wave lithotripsy dominated the spectrum of endourological techniques, recently percutaneous surgery and especially retrograde intra-renal surgery has gained significant importance [1]. This was possible because of the continuous improvements of endourological armamentarium and miniaturization of the instruments [2-8]. Nevertheless, flexible ureteroscopy respectively retrograde intra-renal surgery is limited by ergonomic deficiencies including stone manipulation, laser disintegration or extraction of fragments particularly when treating multiple stones or larger renal calculi
$[9,10]$. Thus, the next level of stone management may represent robot-assisted retrograde intra-renal surgery overcoming most of these technological obstacles.

Similar to robot-assisted laparoscopic surgery, such devices represent master-slave systems (Figure 1) [11-15]. First trials modifying a system designed for cardiology (Hansen, United States) were not very successful due to size limitations and limited mobility in the renal collecting system [11-13]. Since 2010 we were involved in experimental and clinical introduction of the Avicenna Roboflex (Elmed, Ankara, Turkey), which was specifically designed for flexible ureteroscopy $[14,15]$. Beside proof of safe and efficient applicability, the device underwent 
constant improvements by the manufacturer. In this article we want to present the results of the multi-centric phase-II study, (idea, development, evaluation, assessment, long-term study)representing the next step (phase 3) according to the IDEAL

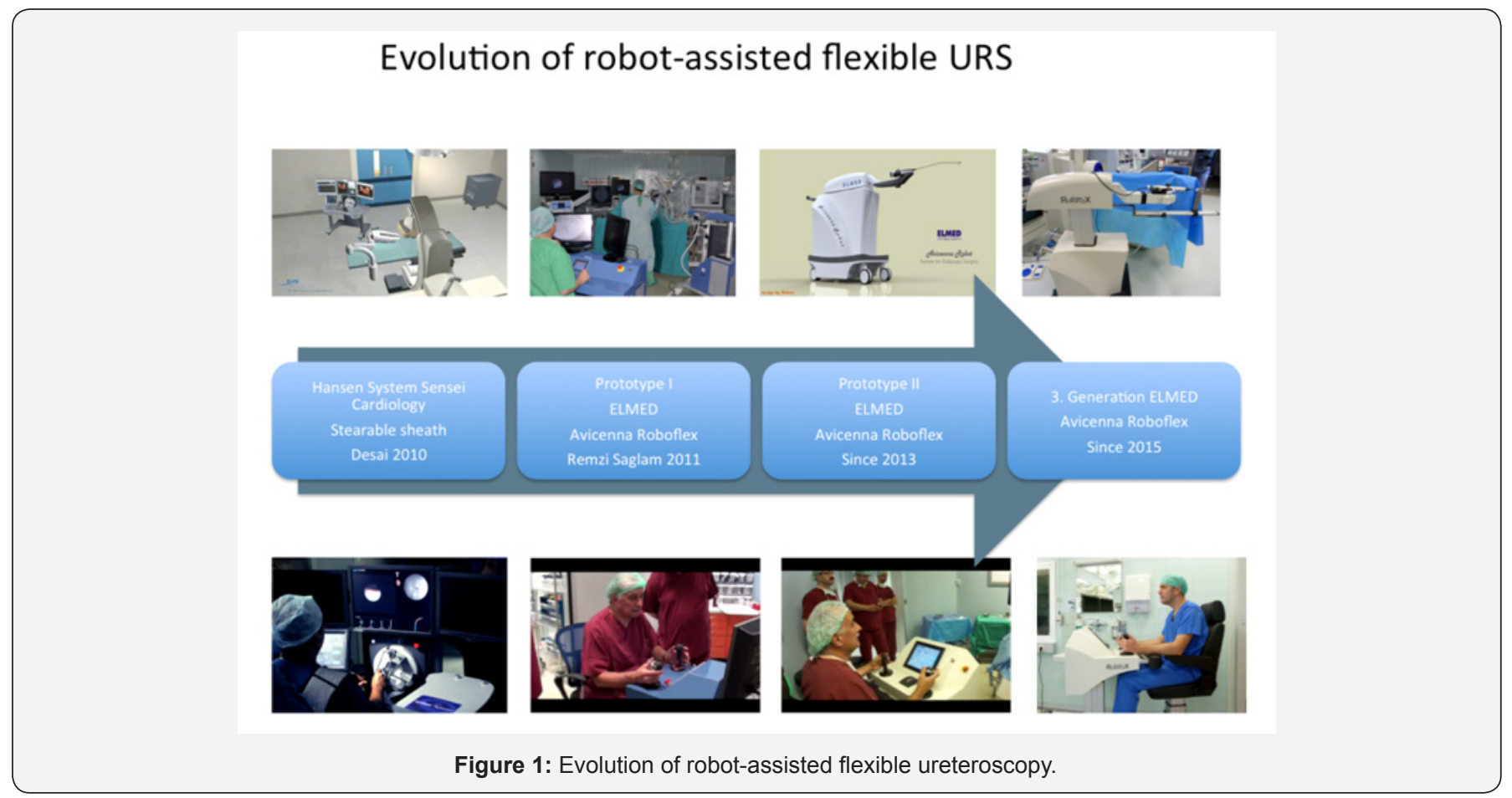

Material and Methods

\section{Specification of the robotic device}

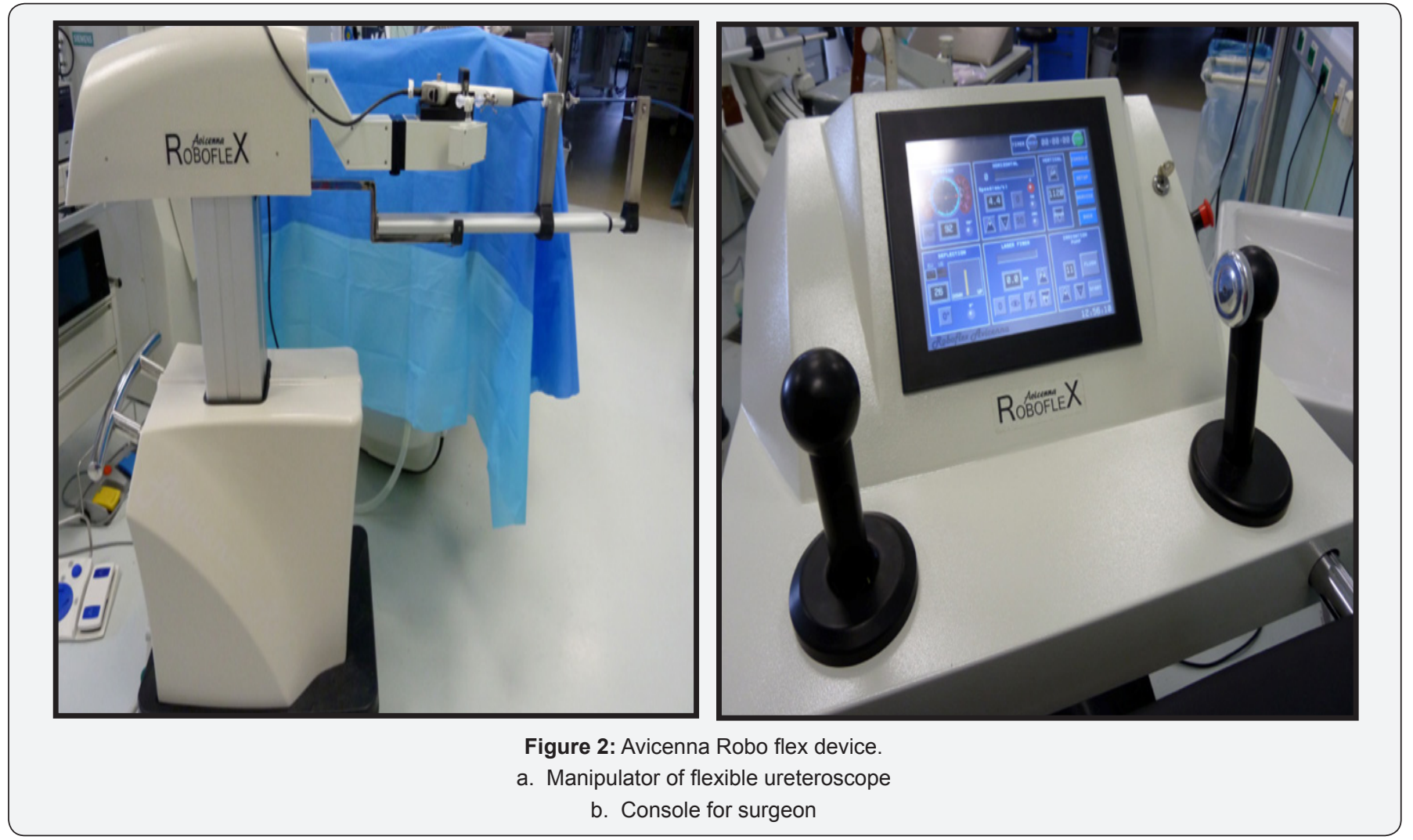


The Avicenna Roboflex consists of a console and the manipulator (Figure 2). The basic functions of the device have been described previously. The main improvements include: o Control of deflection using a wheel for the right hand (Figure 3).

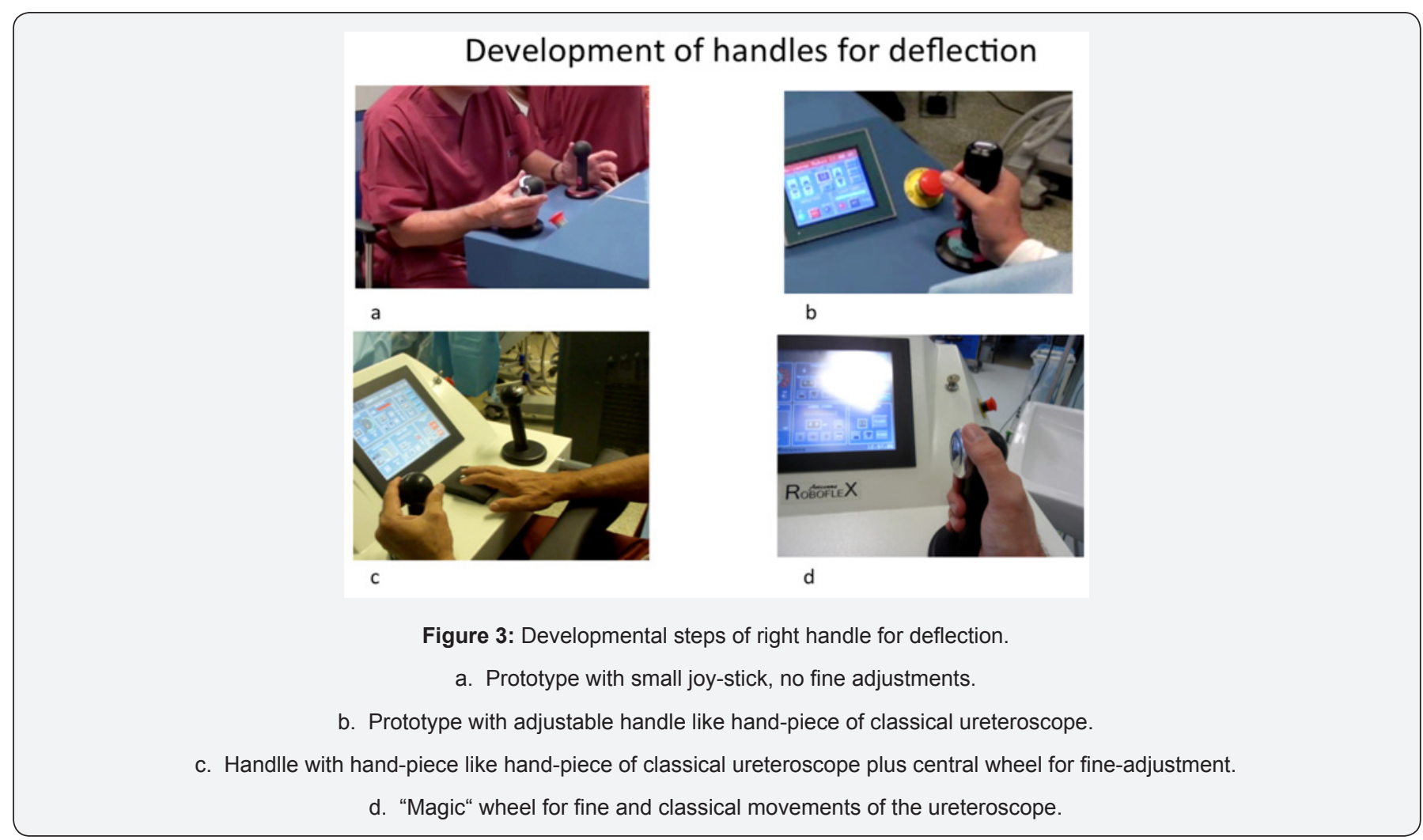

o Control of rotation and horizontal movements via refined joy-stick (Figure 4).

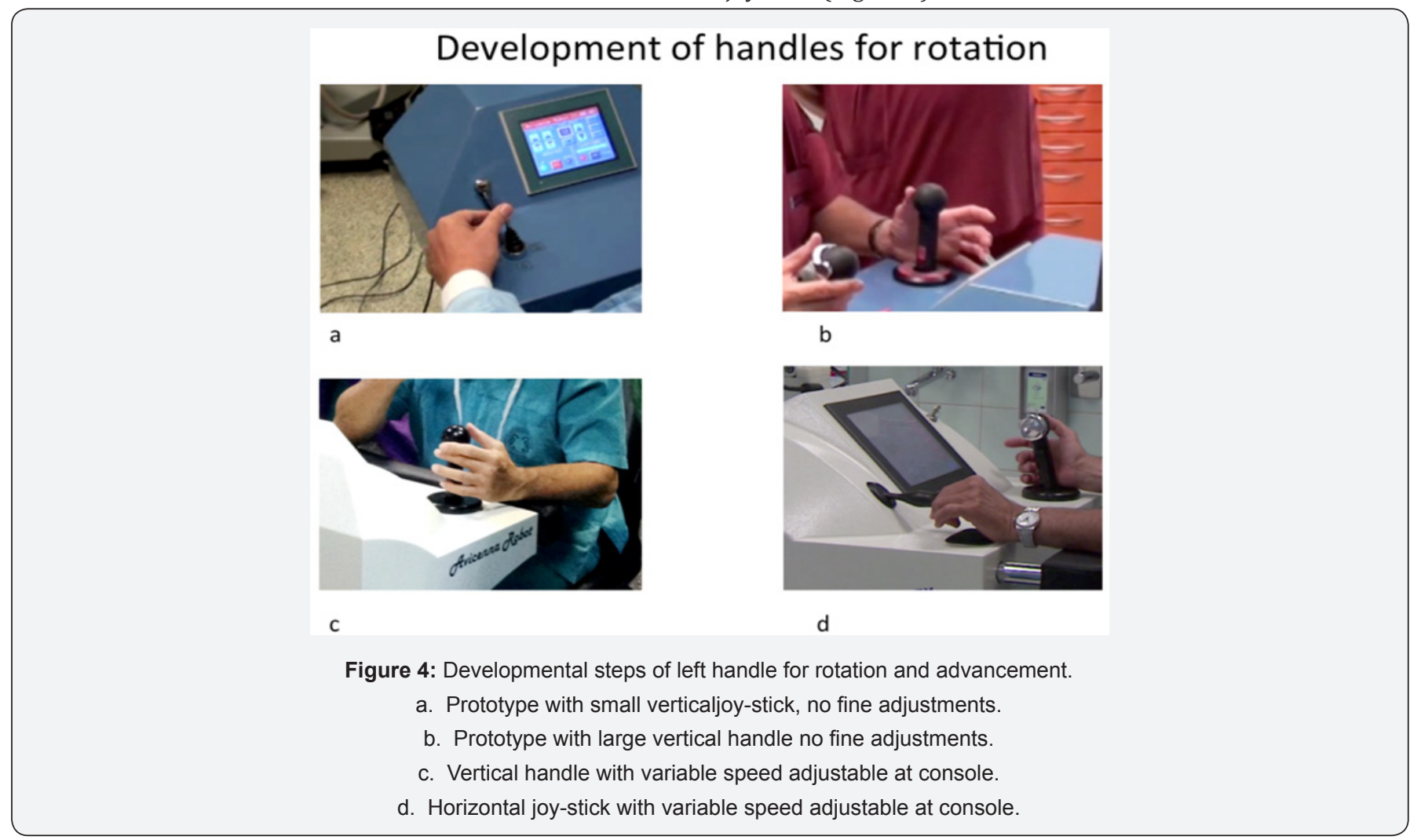


o Integrated HD-monitor displaying the endoscopic view and major data defining the position of the tip of the flexible ureteroscope (Figure 5).

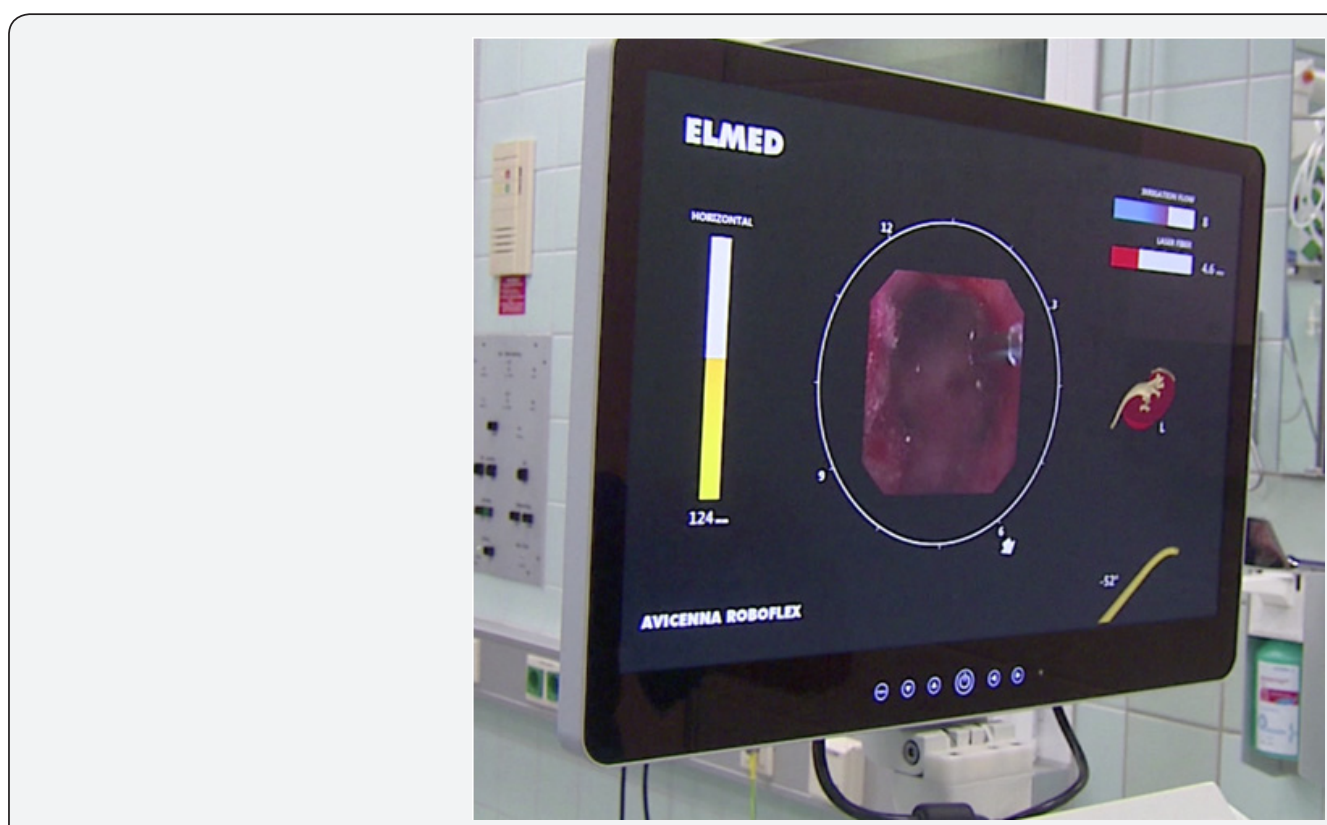

Figure 5: Screen at console showing the endoscopic HD-video with display of additional information (rotation, insertion, positionofscope in collecting system).

o $\quad$ Exchangeable handle for three different digital flexible ureterorenoscopes (Karl Storz Flex X2; Olympus URF-V2; Wolf Cobra digital)

\section{Patient data (Table 1)}

Table 1: Summary of patients data of robot-assisted flexible ureteroscopy $(\mathrm{N}=266)$.

\begin{tabular}{|c|c|c|c|}
\hline Criteria & Value & Range & Comment \\
\hline Age (yrs) & 55 & $25-76$ & No children included \\
\hline \multicolumn{4}{|c|}{ Gender } \\
\hline Male & 176 & & \\
\hline Female & 90 & & \\
\hline Body mass index (BMI) & 29.1 & $20.6-43.3$ & \\
\hline ASA-score (mean) & 2.3 & & \\
\hline \multicolumn{4}{|c|}{ Side of Kidney } \\
\hline right & 118 & & \\
\hline left & 148 & & \\
\hline Mean number of calculi & 1.8 & $1-5$ & $\mathrm{~N}=192$ cases with multiple stones \\
\hline Stone size $(\mathrm{mm})$ & 14 & $5-30$ & Multiple calculi: sum of lenghts \\
\hline Stone volume $\left(\mathrm{mm}^{3}\right)$ & 1620 & $98-10600$ & $\begin{array}{c}\text { Calculated based on preoperative } \\
\text { CT }\end{array}$ \\
\hline No. of patients with stent & 114 & & \\
\hline
\end{tabular}

Following the introduction of the robot in 2 European stone centres (2013 Ankara TR; 2014 Heilbronn, Germany) we collected prospectively peri-operative data from all patients $(n=266)$ who underwent robotic retrograde intra-renal stone surgery (robRIRS) between January 2015 and March 2016. Six different surgeons were involved in the study. We treated 90 o Air driven control unit to activate foot pedals of laser and fluoroscopy females and 176 male patients with a mean age of 55(25-76) years. The body mass index was 29.1(20.6-43.3) and ASA-score side. Mean number of stones was 1.8 with a mean stone burden of $1620(98-10600) \mathrm{mm}^{3} .43 \%$ of the patients were presented. was 2.3. 118 stones were located on the right and 148 on the left 


\section{Treatment protocol}

All stones of this study were treated with the Flex X2ureteroscope (Karl Storz, Tuttlingen, Germany). In all cases we used a $12 / 14 \mathrm{~F}$ access sheath, laser fragmentation was accomplished by use of a high-energy laser device (Lumenis Pulse 100W, United States) applying actual concepts of laser lithotripsy [17] including dusting (low energy (0.2-0.5 J), high frequency (20-40 Hz)), fragmentation (high energy (1.0-1.5 J), low frequency (10-15 Hz)), and the pop-corn/jacuzzi-effect (mid energy (0.5-1.0 J), mid frequency $(20-30 \mathrm{~Hz})$ ). Larger fragments (2-4 mm) were extracted by use of the NGage-device (Cook, Ireland). Recorded performance parameter included set-up time Results of the robot, docking time of the robot, console time to stone contact, overall console time, treatment time, stone clearance rate, $\mathrm{x}$-ray parameters (fluoroscopy time, radiation exposure and desimetry).

\section{Statistics}

Numerical data were expressed as mean with standard deviation (SD) including range; categorical data as number. SPSS program version 15 was used for data analysis. Categorical variables were analysed using Chi-squared test (or Fisher's exact test). Mann-Whitney test was used for numeric variables. P-values less than 0.05 were considered statistically significant.

\section{Intra-operative data (Table 2)}

Table 2: Summary of perioperative results of robot-assisted flexible ureteroscopy ( $N=266)$.

\begin{tabular}{|c|c|c|c|}
\hline Criteria & Value & Range & Comment \\
\hline Time to prepare robot (min) & 4.5 & $3-8$ & $\begin{array}{l}\text { Performed parallel to placement } \\
\text { of access sheath }\end{array}$ \\
\hline No. of patients with access sheath & 266 & & According to protocol \\
\hline Docking time of robot (min) & 4 & $1-29$ & \\
\hline Time to identify stone & 4 & $1-12$ & $\begin{array}{l}\text { Including inspection of collecting } \\
\text { system }\end{array}$ \\
\hline \multicolumn{4}{|c|}{ Operating time } \\
\hline Total & 96 & $58-193$ & \\
\hline Console time & 65 & $16-174$ & \\
\hline No of case with laserlithotripsy & 245 & & Dusting, popcorn / Jacuzzi \\
\hline Stone clearance rate $\left(\mathrm{mm}^{3} / \mathrm{min}\right)$ & 25 & $9-101$ & \\
\hline \multicolumn{4}{|c|}{ Radiation exposure } \\
\hline Mean fluoroscopic time (min) & 2.5 & & $\begin{array}{l}\text { No radiation exposure for surgeon } \\
\text { at console }\end{array}$ \\
\hline Radiation dosis $\left(\mathrm{cGy}^{*} \mathrm{~cm}^{2}\right)$ & 297 & & \\
\hline Technical failure of robot & 2 & & $\begin{array}{c}\text { Conversion to classical FURS / } \\
\text { RIRS }(0.7 \%)\end{array}$ \\
\hline Major complications & 1 & & Urosepis $(0.35 \%)$ \\
\hline Mean hospital stay (d) & 1 & $1-30$ & \\
\hline
\end{tabular}

Preparation of the robot required 4:30min (range 3-8min); docking time was $4 \mathrm{~min}$ (range 1-29min).Console time to visible identification of the stone amounted $4 \mathrm{~min}$ (range 1-12min.), which included inspection of the entire collecting system.

The total operating time was 96min (range 58-193min) including a console time of 65(16-174) min. Laser lithotripsy was performed in 245 patients (92\%), 112(42\%) patients required extraction of larger fragments using $\mathrm{N}$-gage-basket. The stone clearance rate amounted $25(9-101) \mathrm{mm}^{3} / \mathrm{min}$. Total fluoroscopy time was time $2: 30 \mathrm{~min}$ with a radiation dosis of $297 \mathrm{cGy}^{*} \mathrm{~cm}^{2}$. In $117(44 \%)$ of our patients were stented postoperatively of which $75(28 \%)$ had the stent on a string removed on day 1 together with the Foley catheter. In $2(0.7 \%)$ cases we had to convert to classical FURS due to technical failure of the robot.

\section{Post-operative data}

Median postoperative hospital stay was 1(1-30) day. We encountered one case of urosepsis (Clavien 3a) requiring treatment on an intensive care unit.

\section{Discussion}

During the last 15 years robot-assisted surgery has gained an established and irreversible role in urologic laparoscopic surgery $[18,19]$. In 2016, installations of da Vinci-systems increased by $21 \%$ to more than 2,500 units worldwide, and robotic procedures leaped by $25 \%$ to more than 450,000 , mainly performed in urology, gynaecology and visceral surgery [19]. The main advantages of robot-assisted surgery concern significant improvement of ergonomics, which enabled widespread 
application of laparoscopic techniques with acceptable learning curves. Additionally, the use of the robot resulted in better results mainly concerning reconstructive parts of the procedure: e.g. postoperative stenosis of the urethro-vesical anastomosis could be basically eliminated.

However, the use of robotic master-slave-systems is not limited to laparoscopic surgery. Already, in 2008 Desai et al. accomplished to use the Sensei-Magelan-system (Hansen Medical, Mountain View, USA) designed for cardio-vascular interventions by Fred Moll, the inventor of the da Vinci-system to perform robot-assisted flexible ureterorenoscopy $[12,13]$. In this system, the surgeon sits also in front of a console manipulating a steerable flexible tube (Figure 1) usually used for trans-vascular intra-cardiac interventions. The robotic flexible catheter system consists of an outer catheter sheath $(14 / 12 \mathrm{~F})$ and inner catheter guide (12/10F). A 7.5F fibre-optic flexible ureteroscope was inserted through the inner catheter guide. Remote manipulation of the catheter system manoeuvres the ureteroscope tip, which was glued in place to the inner guide. The tip of the outer sheath was positioned at uretero pelvic junction to stabilize navigation of inner guide inside the collecting system. This means that the ureteroscope is manipulated only passively [13]. However, this project has been discontinued because it was difficult to manipulate the ureteroscope passively by use of the steerable tube.

Since 2012, ELMED (Ankara, Turkey) is working on of a robot specifically designed for FURS [14]. Roboflex Avicenna was continuously developed to perform flexible ureteroscopy providing all necessary functions for FURS. It enables the use of different kind of ureteroscopes and holmium-YAG-lasers. The surgeon sits at a console using both hands and feet to control all movements of the endoscope. Compared to manual FURS several functions could be integrated: it enables fine-tuning of the movements, motorized insertion and retraction of the laser fibre, automatic repositioning for introduction of the fibre. This means, that robotic FURS has superior performance qualities compared to the classic procedure. In the first clinical study the positive impact of the system on ergonomics could be verified using a validated questionnaire [15]. However, in this study one urologist (R.S.) being involved in development and clinical introduction of the device proctored all seven surgeons during their cases.

The present study was conducted to assess the real-live scenario when using the device on a daily base in two urologic departments involving six different surgeons. Furthermore, new technical improvements of Avicenna Roboflex were evaluated. Comparing our results with the initial study docking time of the robot was longer ( 4 vs. $1 \mathrm{~min}$ ), time to visualize the stone was similar ( 4 vs. $3.7 \mathrm{~min}$ ) and the console time was longer (96 vs. $53 \mathrm{~min}$ ). However, the stone volume was larger (1620 vs. $1300 \mathrm{~mm}^{3}$ ). Moreover, we were able to demonstrate that we could safely and successfully apply all modern techniques and protocols of flexible URS, such as laser dusting, using pop-corn/ Jacuzzi-effect, and extraction of larger fragments [17].

In this setting, Avicenna Roboflex proved to be robust with only two cases of technical failure requiring conversion to classical FURS. The radiation exposure for the surgeon can be significantly reduced. In conclusion, we were able to integrate the device easily in our daily routine.

The first two clinical studies of Avicenna Roboflex were able to demonstrate safety and efficacy of the system providing significant ergonomic advantages with a very short learning curve for an FURS-experienced surgeon (max 5 cases). Of course, retrograde intra-renal surgery is less complicated compared to laparoscopic radical prostatectomy, particularly in case of small stones, which can be extracted by use of a Nitinol-basket [20]. On the other side, the introduction of the device provides a safe and non-exhausting environment for the surgeon. Based on this we were able to extent the indication of FURS/RIRS to larger intrarenal calculi resulting to decrease of extracorporeal shock wave lithotripsy and percutaneous nephrolithotomy [21,22].

Further studies should now focus to evaluate further the impact of these advantages on the results compared to classical FURS/RIRS. This has to include the analysis of lifetime of the ureteroscopes, requirement of secondary treatment, postoperative complications and radiation exposure to the surgeon [23-26]. The outcomes of these studies are relevant when discussing the costs of the device. In contrast to radiology, where new imaging devices are introduced without proving any costeffectiveness, in surgery the introduction of robotic systems is always associated by cost-discussions.

However, development of robotic systems will never stop. Beyond surgical robots as master-slave devices, the role of robotics might be even extended: Shademan et al. described in-vivo supervised autonomous soft tissue surgery in an open surgical setting, enabled by a plenoptic three-dimensional and near-infrared fluorescent (NIRF) imaging system supporting an autonomous suturing algorithm to complete complex surgical tasks on deformable soft tissue, such as suturing an intestinal anastomosis [27]. Similarly, robot-assisted water-jet-ablation (Procept, Redwood Shores, United States) showed significantly better ablation efficacy compared to standard transurethral resection [28]. Next years will be fascinating to evaluate the impact of robot-assistance for laparoscopy, but also for robotassisted flexible ureterorenoscopy.

\section{References}

1. Preminger GM, Tiselius HG, Assimos DG, Alken P, Buck AC, et al. (2007) 2007 Guideline for the management of ureteral calculi. J Urol 178(6): 2418-2434.

2. Beiko DT, Denstedt JD (2007) Advances in ureterorenoscopy. Urol Clin North Am 34:397-408.

3. Breda A, Ogunyemi O, Leppert JT, Schulam PG (2009) Flexible ureteroscopy and laser lithotripsy for multiple unilateral intra-renal stones. Eur Urol 55(5): 1190-1196. 
4. Patel A, Fuchs GJ (1997) Expanding the horizons of SWL through adjunctive use of retrograde intra-renal surgery: new techniques and indications. J Endourol 11: 33-36.

5. Knoll T, Jessen JP, Honeck P, Wendt-Nordahl G (2011) Flexible ureterorenoscopy versus miniaturized PNL for solitary renal calculi of 10-30mm size. World J Urol 29(6): 755-759.

6. Holden T, Pedro RN, Hendlin K, Durfee W, Monga M (2008) Evidencebased instrumentation for flexible ureteroscopy: A review. J Endourol 22(7): 1423-1426.

7. Somani BK, Aboumarzouk O, Srivastava A, Traxer O (2013) Flexible ureteroscopy: tips and tricks. Urol Ann 5: 1-6.

8. Elkoushy MA, Andonian S (2011) Prevalence of orthopaedic complaints among endourologists are common and their compliance with radiation safety measures very important. Endo urol 25(10): 1609-1613.

9. Healy KA, Pak RW, Cleary RC, Colo-Herdman A, Bagley D (2011) Hand and wrist problems among endourologists are very common. Endourol 25(12): 1905-1920.

10. Rassweiler J, Safi KC, Subotic S, Teber D, Frede T (2005) Robotics and telesurgery-an update on their position in laparoscopic radical prostatectomy. Minim Invasive Ther Allied Technol 14(2): 109-122.

11. Aron M, Haber GP, Desai MM, Gill IS (2007) Flexible robotics: a new paradigm. Curr Opin Urol 17(3): 151-155.

12. Desai MM, Aron M, Inderbir SG, Pascal-Haber Ukimura O, Kaouk JH, et al. (2008) Flexible Robotic Retrograde Renoscopy: Description of Novel Robotic Device and Preliminary Laboratory Experience. Urology 72: $42-46$

13. Desai MM, Grover R, Aron M, Ganpule A, Joshi SS, et al. (2011) Robotic flexible ureteroscopy for renal calculi: initial clinical experience. J Uro 186(2): 563-568.

14. Saglam R, Kabakci AS, Koruk E, Tokatli Z (2014) How did we designed and improved a new Turkish robot for flexible ureterorenoscopy. J Endourol 66(6): 1092-1100.

15. Saglam R, Muslumanoglu AY, Tokatlı Z, Caşkurlu T, Sarica K, et al. (2014) A New Robot for Flexible Ureteroscopy: Development and Early Clinical Results (IDEAL Stage 1-2b). Eur Urol 66(6): 1092-1100.

16. Dahm P, Sedrakyan A, McCulloch P (2014) Application of the IDEAL framework to robotic urologic surgery. Eur Urol 65(5): 849-851.
17. Kronenberg P, Traxer 0 (2013) In-vitro fragmentation efficiency of holmium: yttrium-aluminum-garnet (YAG) laser lithotripsy - a comprehensive study encompassing different frequencies, pulse energies, total power levels and laser fibre diameters. BJU Int 114(2): 261-267.

18. Teber D, Baumhauer M, Guven EO, Rassweiler J (2009) Robotics and imaging in urological surgery. Curr Opin Urol 19(1): 108-113.

19. Ghezzi, L andCorleta C (2016) 30 years of robotic surgery. World J Surg 40(10): 2550-2557.

20. Tokatli Z, Muslumanoglu AY, Binbay M, Tepeler A, Suer E, et al. (2013) How long it takes to learn to use Roboflex Avicenna for flexible ureterorenoscopy, comparison of an experienced users and trainees. J Endo Urol 27(suppl 1): A223.

21. Schout BM, Hendrikx AJ, Scherpbier AJ, Bemelmans BL (2008) Update on training models in endo urology: a qualitative systematic review of the literature between January 1980 and April 2008. Eur Urol 54(6): 1247-1261.

22. Türk C, Knoll T, Petrik A, Sarica K, Seitz C, et al. (2012) Guidelines on Urolithiasis. European Association of Urology.

23. Carey RI, Gomez CS, Maurici G, Lynne CM, Leveillee RJ, et al. (2006) Frequency of ureteroscope damage seen at a tertiary care center. J Urol 176(2): 607-610.

24. Bagley DH, Cubler-Goodman A (1990) Radiation exposure during ureteroscopy. J Urol 14496): 1356-1358.

25. Hellawell GO, Mutch SJ, Thevendran G, Wells E, Morgan RJ (2005) Radiation exposure and the urologist: what are the risks? J Urol 174(3): 948-952.

26. Kim KP, Miller DL, Berrington de Gonzalez A, Balter S, Kleinerman RA, et al. (2012) Occupational radiation doses to operators performing fluoroscopically-guided procedures. Health Phys 103(1): 80-99.

27. Shademan A, Decker RS, Opfermann JD, Leonard S, Krieger A, et al (2016) Supervised autonomous robotic soft tissue surgery. SciTransl Med 8(337): 337-342.

28. Gilling P, Reuther R, Kahokehr A, Fraundorfer M (2016) Aquablation - image-guided robot-assisted waterjet ablation. BJU Int 117(6): 923929.

\section{Your next submission with Juniper Publishers} will reach you the below assets

- Quality Editorial service

- Swift Peer Review

- Reprints availability

- E-prints Service

- Manuscript Podcast for convenient understanding

- Global attainment for your research

- Manuscript accessibility in different formats

( Pdf, E-pub, Full Text, Audio)

- Unceasing customer service

Track the below URL for one-step submission https://juniperpublishers.com/online-submission.php 